\title{
Lip Pits and Congenital Absence of Second Premolars: Varied Expression of the Lip Pits Syndrome*
}

\author{
EDWARD L. SCHNEIDER $†$ \\ Department of Pediatrics, University of California-San Francisco; San Francisco, California 94122, USA
}

Summary. A family with the lip pits syndrome is described in which nine of the 11 affected members have hypodontia involving the second premolars.

The familial occurrence of lower lip pits (fistulas, sinuses) was first described by Dermarquay in 1845 . Family studies indicate that this congenital malformation is inherited as an autosomal dominant trait with high penetrance $(80 \%)$ and with expression which varies from a single barely noticeable lower lip depression to upper cleft lip and/or palate (Cervenka, Gorlin, and Anderson, 1967). The most common lesions are two fistulas which appear as pits on the vermilion part of the lower lip, equidistant from the midline. In addition to cleft lip and/or palate, other less frequently associated anomalies include syndactyly of the hands, polythelia, ankyloglossia, and symblepharon (Cervenka et al, 1967).

The family reported here prominently displays an association of lower lip pits and hypodontia, involving the mandibular and maxillary second premolars. Since missing third molars are extraordinarily common $(25 \%)$ in the general population, the hypodontia under discussion concerns the remaining 28 teeth (Werther and Rothenberg, 1939).

\section{Materials and Methods}

Family B came to our attention when an unaffected member of the family (III.12) came to our clinic for genetic counselling on an unrelated matter. Subsequently, 27 members of family B were personally examined and information on 11 other members was obtained by a questionnaire. Of the latter group, three are deceased and one is institutionalized with Down's syndrome. Full mouth $x$-rays were done on three

Received 7 June 1973.

* This work was aided by grants from the National FoundationMarch of Dimes, Maternal and Child Health Service (USPHS), and the National Institute of General Medical Sciences, USPHS.

† Present address: Mammalian Genetics Section, Laboratory of Cellular and Comparative Physiology, Gerontology Research Center, Baltimore City Hospitals, Baltimore, Maryland 21224, USA. family members. Red blood cell and serum samples were obtained from 16 family members, including nine with lip pits. The following red blood cell antigen systems were analysed: $\mathrm{A}, \mathrm{B}, \mathrm{O}, \mathrm{Rh}(\mathrm{C}, \mathrm{D}, \mathrm{E}, \mathrm{c})$, Lewis $\left(\mathrm{Le}^{\mathrm{a}}, \mathrm{Le}^{\mathrm{b}}\right)$, MNSs, Duffy $\left(\mathrm{Fy}^{\mathrm{a}}\right)$, Kidd $\left(\mathrm{JK}^{\mathrm{a}}\right)$, Kell, and $\mathbf{P}$ (Giblet, 1969). Electrophoresis was performed on red blood cells for haemoglobin, glucose-6-phosphate dehydrogenase, and phosphoglucomutase types and serum for haptoglobin types (Sparkes, Baluda, and Townsend, 1969; Petrakis, Lee, and Mossberger, 1973).

\section{Results}

Inheritance. The pedigree of family $B$ is shown in Fig. 1. Eleven of the $27(41 \%)$ members examined had either unilateral (Cervenka et al, 1967) or bilateral (Brechkus, Oliver, and Montelius, 1944) pits in the anterior paramedian vermilion portion of the lip (Figs. 2a and 2b). The presence of lip pits in two deceased family members, was documented by photographs. The high incidence of lip pits in offspring of affected members (12 of 21 or $57 \%$ ), the vertical transmission through three generations and father to son transmission indicate autosomal dominant inheritance.

Associated Hypodontia. As is shown in Table I, nine of the 11 examined family members with lip pits had less than 28 teeth present (third molars excluded). By contrast, none of the 12 family members without lip pits but with permanent dentition had missing teeth. That this is not a fortuitous association is indicated by chi-square testing, which reveals a highly significant correlation between lip pits and hypodontia (less than 28 teeth). Of the nine patients with lip pits and hypodontia, four have missing maxillary and mandibular second premolars while five have missing mandibular second premolars only. One patient (II.3) with missing mandibular second premolars also had 


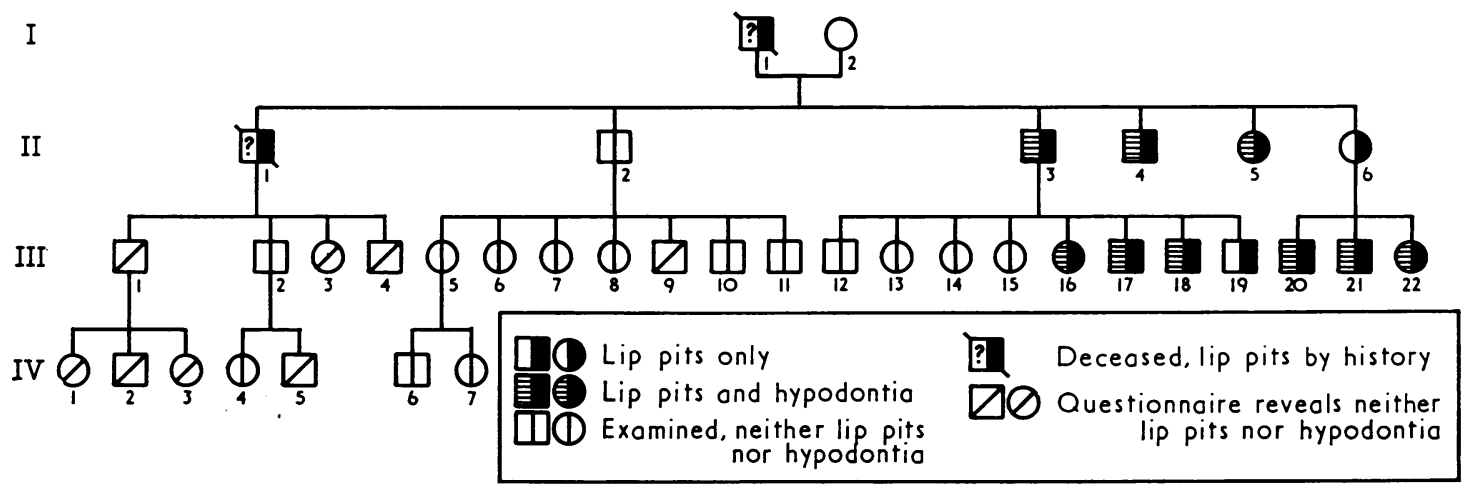

Fig. 1. Pecigree of family $\mathbf{B}$.

TABLE I

PRESENCE OF HYPODONTIA IN PATIENTS WITH LIP PITS

\begin{tabular}{l|c|c}
\hline & $\begin{array}{c}\text { Normal Dentition* } \\
(>28 \text { teeth })\end{array}$ & $\begin{array}{c}\text { Hypodontia* } \\
(<28 \text { teeth })\end{array}$ \\
\hline $\begin{array}{l}\text { Affected individuals } \\
\text { Lip pits only } \\
\begin{array}{l}\text { Unilateral } \\
\text { Bilateral }\end{array}\end{array}$ & 0 & 2 \\
\hline $\begin{array}{l}\text { Lip pits and cleft lip and } \\
\text { palate }\end{array}$ & 2 & 5 \\
\hline Total & 0 & 2 \\
\hline Unaffected individuals & $2 \dagger$ & $9+$ \\
\hline
\end{tabular}

* Excluding third molars.

$+x^{2}=12.9, \mathrm{p} \ll 0.001$.

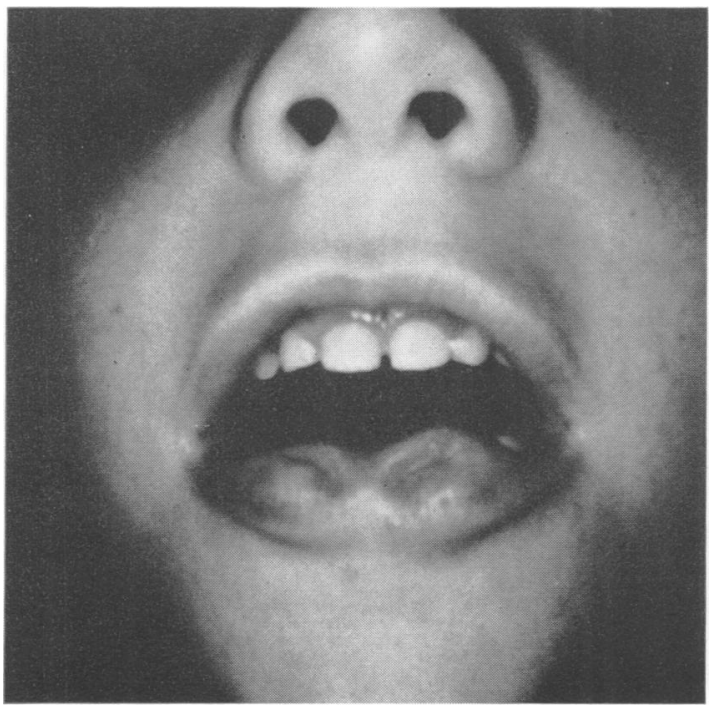

FIG. 2a. Bilateral lip pits observed in III.19. one missing upper lateral incisor (Fig. 3a). Oral radiology of this patient's son (III.19) revealed the more commonly observed pattern of missing mandibular second premolars only (Fig. 3b).

Other Malformations. Cleft lip and palate were observed in two family members (II.4 and III.16) with both lip pits and hypodontia. Ptyergia, syndactyly, ectodermal dysplasia, or other malformations were not observed in affected family members. One person without lip pits had Down's syndrome and another died of congenital heart disease (tetralogy of Fallot).

Red Blood Cell Antigen and Other Genetic Studies. The results of red blood cell antigen

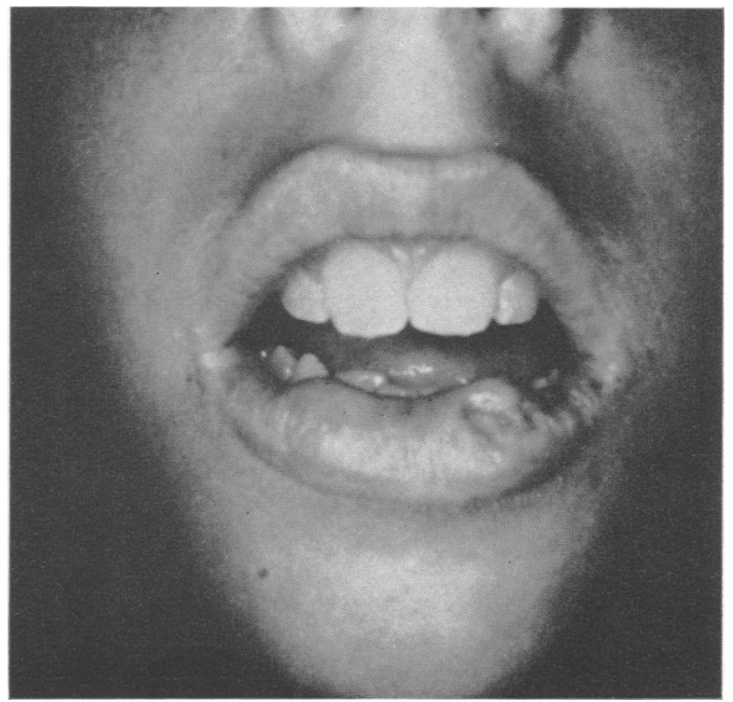

FIG. 2b. Unilateral lip pit observed in III.17. 


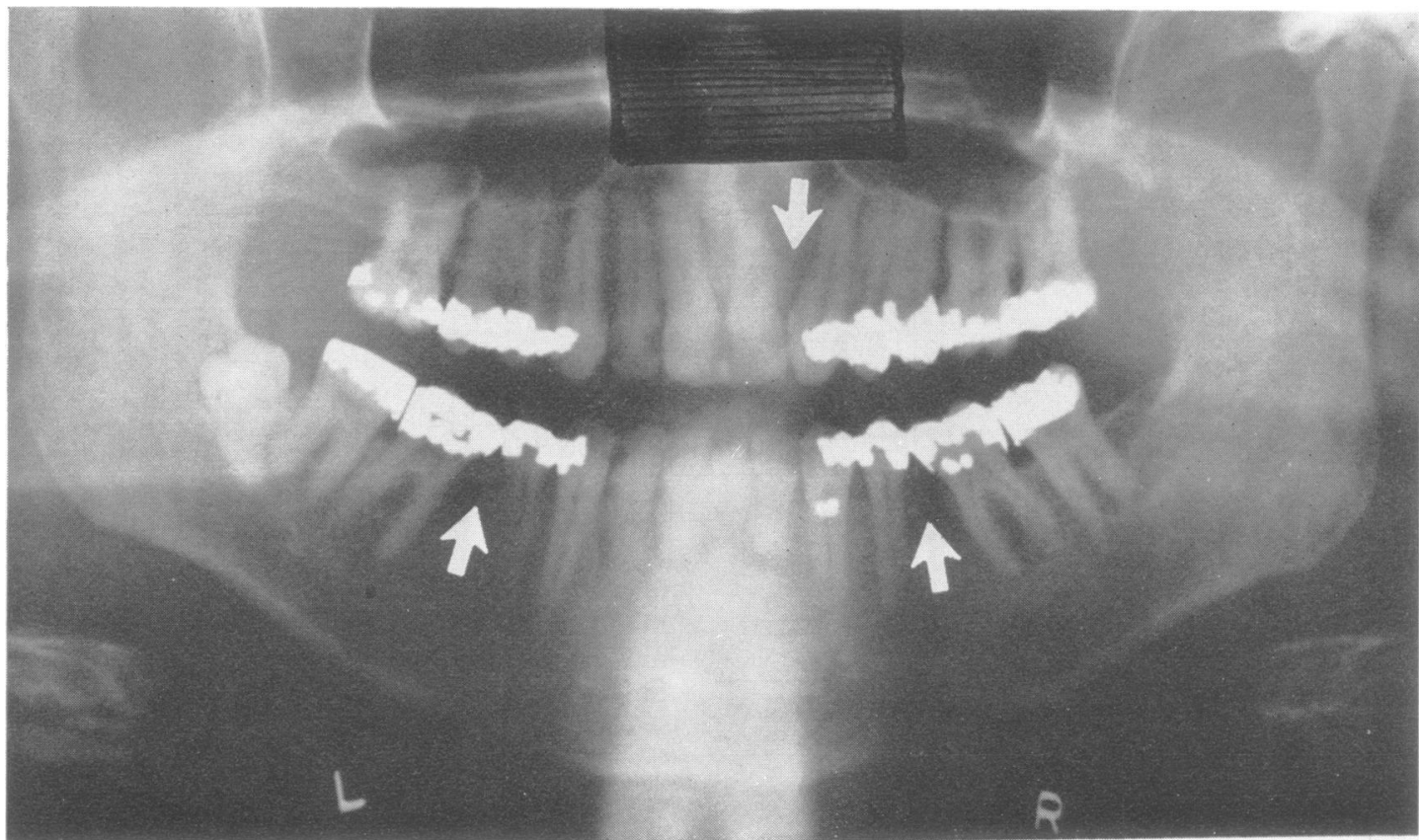

FIG. 3a. Full mouth radiograph of II.3 revealing absent bilateral mandibular second premolars and right lateral maxillary incisor (arrows),
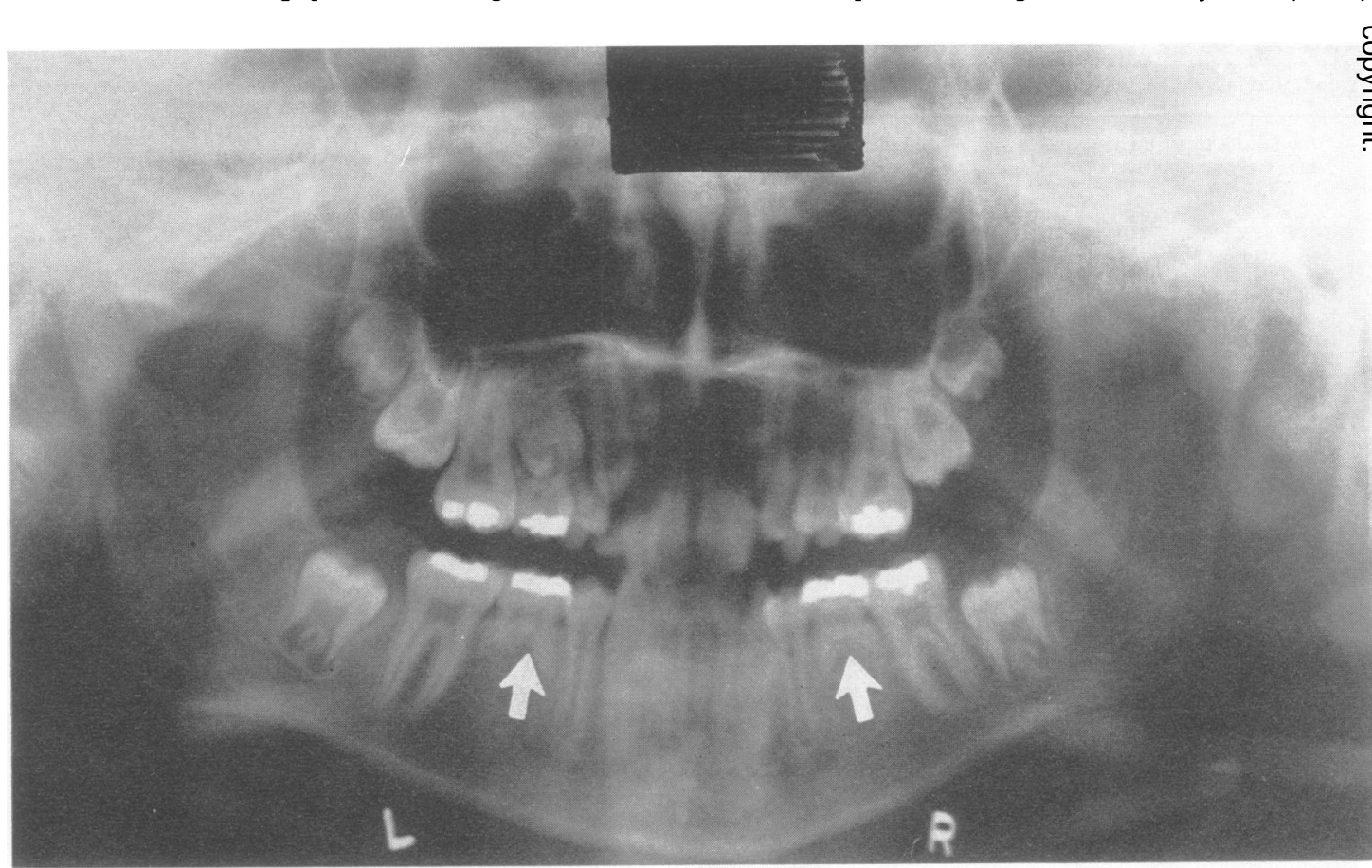

$\overrightarrow{6}$

○े సे ○

FIG. 3b. Full mouth radiograph of III.18 revealing absent bilateral permanent mandibular second premolars with only deciduous mandibular second premolars present (arrows). 
analysis as well as electrophoretic studies on haptoglobin, glucose-6-phosphate-dehydrogenase, phosphoglucomutase, and haemoglobin revealed no apparent linkage to either lip pits or missing teeth.

\section{Discussion}

Congenital missing teeth is not an uncommon finding with an incidence, if third molars are excluded, of between 3 and $6 \%$ (Breckhus et al, 1944; Gates, 1946; Grahnen, 1962). The most frequently involved teeth, excluding third molars, are the maxillary incisors and the maxillary and mandibular premolars (Breckhus et al, 1944; Gates, 1946; Grahnen, 1962). Families have been described with apparent autosomal dominant transmission of missing maxillary lateral incisors, maxillary canines, maxillary central incisors, and various other less consistent combinations (Breckhus et al, 1944; Gates, 1946; Grahnen, 1962). Erwin and Corkern (1949) described a family with dominant transmission of absent maxillary and mandibular second premolars. This family differs from family $B$ in that three of the four members affected had various additional missing teeth including lateral maxillary incisors, mandibular central incisors and maxillary first bicuspids.

Cases of hypodontia have occurred in conjunction with ectodermal dysplasia, but lip pits have not been observed (Grahnen, 1962). Conversely, reviews of the syndrome of congenital lip pits do not mention hypodontia (Watanabe, IgakuHakushi, and Tomida, 1951; Neuman and Shulman, 1961; Cervenka et al, 1967; Hoffman, 1971). Cervenka et al (1967) in their review noted considerable heterogeneity in the expression of the lip pit syndrome, with some families having a higher frequency of cleft lip and/or palate. The family described in this report may represent another aspect of this heterogeneity. In this case, hypodontia may have high expression ( $81 \%$ ) and cleft lip and/or palate low expression $(<20 \%)$. Hypodontia therefore may be a feature of this syndrome which has been overlooked in previous families.

Another possibility is that this family has two separate, dominantly inherited disorders, the syn- drome of lip pits and a syndrome of congenital absence of the second premolars (mandibular with or without maxillary). Pedigree analysis would suggest that if this is the case, there is close linkage between these two genes. There is a possibility that lip pits in association with missing second premolar represents a new syndrome with autosomal dominant inheritance. In either case, one clinically important observation is the low risk of recurrence $(<10 \%)$ for the more severe associated condition, cleft lip and/or palate.

I would like to thank Dr Merle Morriss for dental consultation, Drs R. Mossberger and N. Petrakis for the electrophoretic studies, Mrs E. B. for help in arranging examinations of family B, Dr. D. P. Hause for use of his photographs, and Drs C. J. Epstein and Bryan Hall for editorial assistance.

\section{REFERENCES}

Breckhus, P. J., Oliver, C. P., and Montelius, G. (1944). A study of the pattern and combinations of congenitally missing teeth in man. fournal of Dental Research, 23, 117-131.

Cervenka, J., Gorlin, R. J., and Anderson, V. E. (1967). The syndrome of pits of the lower lip and cleft lip and/or palate. Genetic considerations. American fournal of Human Genetics, 19, 416432.

Demarquay, J. N. (1845). Quelques considerations sur le bec-delievre. Gazette Médicale de Paris, 13, 52-54.

Erwin, W. G. and Corkern, R. W. (1949). A pedigree of partial anodontia. Fournal of Heredity, 40, 215-218.

Gates, R. R. (1946). Human Genetics. Macmillan, New York.

Giblet, E. R. (1969). Genetic Markers in Human Blood. Blackwell Scientific, London.

Grahnen, H. (1962). Hereditary factors in relation to dental caries and congenital missing teeth. In Genetics and Dental Health, ed. by J. Witcop, Jr. McGraw-Hill, New York.

Hoffman, S. (1971). Congenital lip sinuses: hereditary aspects and their relationship to cleft lip and palate. British fournal of Plastic Surgery, 24, 241-246.

Neuman, Z. and Shulman, J. (1961). Congenital sinuses of the lower lip. Oral Surgery, Oral Medicine and Oral Pathology, 14, 1415-1420.

Petrakis, N., Lee, R., and Mossberger, R. (1973). Cellulose acetate electrophoresis of human red cell phosphoglucomutase and polyacrylamide gel electrophoresis of human haptoglobins. (Unpublished data.)

Sparkes, R. S., Baluda, M. C., and Townsend, D. E. (1969). Cellulose acetate electrophoresis of human glucose-6-phosphate dehydrogenase. Fournal of Laboratory and Clinical Medicine, 73, 531-534.

Watanabe, Y., Igaku-Hakushi, M. O., and Tomida, K. (1951). Congenital fistulas of the lower lip. Oral Surgery, Oral Medicine and Oral Pathology, 4, 709-722.

Werther, R. and Rothenberg, F. (1939). Anodontia: a review of its etiology with presentation of a case. American fournal of Orthodontics, 25, 61-81. 